\title{
Концепт «сверхчеловек» и демонические герои Достоевского в русской эссеистике Серебряного века
}

\author{
ÁGNES DUKKON \\ ELTE BTK Orosz Nyelvi és Irodalmi Tanszék, H-1088 Budapest, Múzeum krt. 4/D. \\ Department of Russian Language and Literature, Faculty of Humanities, Eötvös Loránd University \\ E-mail: dukkonagnes@gmail.com
}

(Received: 2 December 2017; accepted: 25 February 2018)

\begin{abstract}
The paper deals with the interpretations of the concept "сверхчеловек" in the Russian literature and philosophy of the Silver Age. The focus of the investigation is on the questions of similarities and differences between Nietzsche's "Übermensch" and the Russian concept of "сверхчеловек" as well as the revival of the romantic cult of "demon", i.e. the rebellious hero (from Lermontov to Dostoevsky) at the end of the 19th century. The reflections of these questions in the essays of Vl. Solov'ev, S. Znamensky, I. Annensky, and V. Ivanov are studied, and the author tries to point out the connections between the "demonic figures" of Dostoevsky and certain meanings of the concept of "сверхчеловек".
\end{abstract}

Keywords: Übermensch, Dostoevsky, Lermontov, Demon, rebellious hero, Silver Age

В настоящей статье мы постараемся указать на некоторые соприкосновения между великими образами Достоевского и концептом «сверхчеловек», ставшим по трудам Ницше одним из самых животрепещущих философских понятий второй половины XIX века. Восприятие Достоевского на рубеже XIX-XX веков и в последующие десятилетия составляет большой, органичный контекст, отдельные «голоса» которого часто вступают в диалог и в полемику друг с другом. В статье В. А. Келдыша «Наследие Достоевского и русская мысль порубежной эпохи» (КЕлдыш 1992) дается исчерпывающий анализ темы, но с тех пор появился ряд новых работ, сборники и монографии, разрабатывающие многосложные аспекты истолкования Достоевского в период модернизма (см. КАСАТКинА 2007, БогдАНовА 2008). Такая же богатая специальная литература занимается и вопросами русского ницшеанства и сопоставления антропологии Достоевского и Ницше; среди них можно упомянуть книгу Р. Л. Джексона, в которой одна глава посвящена концепции «сверхчеловек» у Ницше и Достоевского (JACKSON 1993: 237-250). Поскольку весь объем темы не вмещается в рамки данной работы, мы уделим внимание вопросу того, в каком литературном и культурном окружении соприкасаются т. н. «демонические» фигуры Достоевского с понятием сверхчеловека в начале XX века; из богатой литературы мы сосредоточимся в первую очередь на работах, развертывающих взгляды Владимира Соловьева, Иннокентия Анненского и Вячеслава Иванова. 
Начиная с критики Н. К. Михайловского («Жестокий талант», 1882) и письма Н. Страхова Льву Толстому о Достоевском, в котором он отождествлял писателя с его темными героями, ${ }^{1}$ до литературной и религиозно-философской эссеистики Серебряного века, сложные, «демонические» герои Достоевского остаются в центре внимания критики; однако с конца XIX в. уже не являются объектами одностороннего морального осуждения, а скорее выступают как фигуры, несущие загадочные, символические значения. В большинстве случаев истолкователи усматривают в них представителей отрицательных или опасных, обоюдоострых философских идей, с которыми они ведут разнообразную, многоголосую полемику - минимум в трех плоскостях (с самим писателем, образами и идеями героев). Сергий Булгаков - в связи с недостатками рецепции Достоевского российской интеллигенцией - в своей лекции, прозвучавшей 21 ноября 1901 г. в Киеве, критикует состояние русской философии, т. е. рассуждает о причинах неосуществления самобытной русской философии. Однако, с другой стороны, этот недостаток создает некую новую ценность в литературе: «... та сила мысли нашего народа, которая не выразилась в научных трактатах, нашла для себя исход в художественных образах...» (БулгАКов 1991: 194). С. Булгаков упоминает творчество Достоевского, Толстого, Тургенева и Чехова, в произведениях которых скоплены самые глубокие мысли о человеке, о жизни и смерти, и - как он подчеркивает - «нужно уметь оценить их». Именно в связи с духовным наследием Достоевского Булгаков отмечает отсутствие этой нужной оценки:

Может быть, это делается относительно Тургенева, Толстого и наших современных писателей, но этого не сделается еще относительно великого страдальца нашей литературы, Достоевского.

Он остается как бы забыт в нашей передовой литературе, около его священного имени скопляются обидные недоразумения, благодаря которым его считают чуть не своим рептилии литературы, а лучшая часть общества не чувствует своей кровной с ним связи (БулГАКОВ 1991: 194).

Понятие сверхчеловека в 1880-1890-е годы в России связывается с философией Фридриха Ницше и Владимира Соловьева, чье влияние на литераторов и мыслителей Серебряного века является бесспорным. В центре пневматологии и антропологии Соловьева стоит преображенный, перерожденный человек, который имеет непосредственное отношение к Богочеловеку, т. е. конечному, абсолютному, божественному Первообразу. По убеждению Соловьева человек может (и должен) стремиться к обожению, перерастать свои земные, материальные пределы и становиться духовным, христообразным человеком. В его понимании «сверхчеловек» - это духовный человек, который - осознавая свое несовершенство - беспредельно стремится к лучшему, высшему уровню человеческого бытия. Глубокие толкования этого вопроса

${ }^{1}$ «Он был зол, завистлив, развратен... Лица, наиболее на него похожие, - это герой „Записок из подполья“, Свидригайлов в „Преступлении и наказании“ и Ставрогин в „Бесах“» (цит. по КЕЛдЫш 1992: 82). 
даны в статьях Соловьева, опубликованных в 1899 г.: «Лермонтов» (СоловьЕВ 1990а) и «Идея сверхчеловека» (Соловьев 1990b). Они возникли под единым вдохновением, о чем свидетельствуют переклички главных утверждений философа в обеих работах. В личности и творчестве Лермонтова он усматривает более раннее появление сверхчеловеческого образа - но в несовершенном виде. Точнее, Соловьев думает, что поэт - по причине своей бунтующей, гордой натуры - утратил тот идеал, который в лучшие минуты озарил его мысли и дух (Дуккон 2014). Основной тезис Соловьева формулируется так:

Можно спорить о метафизическом вопросе безусловной свободы выбора, но самодеятельность человека, т. е. его способность действовать по внутреннему побуждению, - окончательно по сознанию долга или по совести, - есть не метафизический вопрос, а факт опыта. Вся история состоит в том, что человек делается лучше и больше самого себя, перерастает свою наличную действительность, отодвигая ее в прошедшее, а в настоящее вдвигая то, что еще недавно было противоположным действительности, мечтою, субъективным идеализмом, утопией. Внутренний, духовный, самодеятельный рост есть такой же бесспорный факт, как и рост внешний, физический, пассивный, с которым он связан как с своим предположением.

Теперь спрашивается, в каком же направлении, с какой стороны жизни должно совершаться изменение данного человечества в лучшее и высшее - в «сверхчеловечество» (СоловьЕв 1990а: 275).

В Санкт-Петербурге в 2001 году была издана антология «Ницше: Pro et contra», представляющая очень богатую картину русского ницшеведения, и в которой собраны эссе выдающихся российских писателей и мыслителей первой трети XX века. Среди работ 22 авторов упомянем статьи В. С. Соловьева, Л. Шестова, В. И. Иванова, А. Белого, Л. Троцкого, А. Ф. Лосева. Работы В. С. Соловьева и С. П. Знаменского представляют для нас особенно интересные точки зрения к анализу феномена «сверхчеловек».

Вышеупомянутая статья Соловьева «Идея сверхчеловека», переизданная в этом сборнике, реагирует на культ Ницше и демоническое понимание сверхчеловека, характерное для русской интеллигенции конца XIX века. Он полемизирует с этим толкованием и освещает идею Ницше с положительной стороны. Понятие Übermensch скрывает в себе и ложные, и верные содержания, и допускает даже совсем противоположные интерпретации, как об этом свидетельствуют многочисленные толкования в Европе и России. Если «сверхчеловек» понимается как идеал, как цель внутреннего обновления, и ради этого идеала мы критически смотрим на свое несовершенство, осуждаем самих себя, то стремление к нему действительно ведет нас вперед. По Соловьеву, внутренний рост для человечества есть данность: именно он выделяет его из природного, животного мира и делает возможным духовное перерождение. «Новый человек» морфологически не изменяется, но благодаря внутреннему росту он поднимается на высший уровень человеческого бытия, образцом которого есть Богочеловек, Иисус Христос. Ставка сверхчеловеческого статуса не меньшая, чем победа над смертью, воскресение, но 
человек в этой борьбе может быть победителем лишь при помощи Бога: рост внутреннего человека совершается в «сотрудничестве» с Богом. В итоге размышлений Вл. Соловьева еще раз подчеркивается утверждение, которое уже прозвучало и в статье «Лермонтов»: на пути становления сверхчеловека совершается перерождение смертного и страдающего человека в бессмертного и блаженного сверхчеловека. И поэтому, идею Ницше можно воспринимать в положительном смысле, так как философ обратил внимание на самые существенные вопросы человечества. Ницше не дал однозначного ответа на поставленные вопросы; различные толкования вытекают именно из этого обстоятельства, в том числе и декадентские, «демонические» интерпретации на рубеже XIX-XX веков. Одну из оригинальных интерпретаций мы находим у Вячеслава Иванова в эссе «Ницше и Дионис», в котором он связывает проблему «сверхчеловека» с «дионисийством» Ницше, т. е. указывает на близость концепта трагического бога и сверхчеловеческого бытия. По словам Иванова, «спящие в нас возможности человеческой божественности заставили нас вздохнуть о трагическом образе Сверхчеловека - о воплощении в нас воскресшего Диониса» (ИвАнов 1971: 716). И хотя мифический древнегреческий бог или его атрибуты у символистов иногда сближаются с образом Богочеловека (см. финал поэмы А. Блока «Двенадцать»), у Соловьева эти образы не смешиваются, а у Иванова это сближение появляется лишь гипотетически, как эстетическое выражение проблемы перерождения человека.

Один из менее известных авторов антологии, С. П. Знаменский, священник и религиозный публицист в обстоятельной статье «,Сверхчеловек“ Ницше» (первое издание: 1909 г.) анализирует феномен Übermensch, указывая и на филологические связи самого слова (ЗНАмЕНский 2001). Как автор предполагает, Ницше мог заимствовать его из «Фауста» Гёте: дух земли иронически называет Фауста «сверхчеловеком», который испытывает страх при появлении высших, стихийных сил, вызванных им: «Welch’ erbärmlich Grauen / Faßt Übermenschen dich!» [Какой жалкий страх овладевает тобою, сверхчеловек!] (GoETHE 1972: 147). Знаменский утверждает, что во взглядах на сверхчеловека у Ницше появляется двойственность; в некоторых произведениях - в том числе и в «Так говорил Заратустра»- он разделяет эволюционную теорию Дарвина, и сверхчеловек понимается как особый биологический вид, который превосходит человека в такой степени, как этот последний превосходит обезьяну. А в более поздних трудах - например, в «Антихристе»- переосмысляется дарвинистическая концепция, и сверхчеловек определяется как наиболее совершенный тип человека. «Итак, по другой концепции, которую можно назвать культурно-исторической, сверхчеловек есть только homo sapiens perfectus, - совершеннейший человеческий тип» (ЗНАмЕНский 2001: 933).

Для нашего исследования являются особенно ценными мысли Знаменского о различии и схожести идеала «сверхчеловека» в философии Ницше и в христианском понимании: первый остается в этических пределах земного существования как конечная стадия развития, а христианский взгляд открывает для человека беспредельные, космические перспективы духовного пре- 
ображения, обожения человека по образцу Богочеловека. Тем не менее автор уделяет большое внимание и созвучиям между христианским и ницшеанским идеалами: в обеих концепциях самоосуждение и стремление к самосовершенствованию остаются самым важным критерием достижения цели. Новизна анализа Знаменского состоит в том, что со стороны официального православия он первый подошел к философии Ницше без предвзятостей, с глубоким пониманием, и увидел в ней ценные элементы, как например провозглашение уникальности человеческой личности и призыв к развертыванию заложенных в человеке высших способностей. Иисус Христос в Нагорной проповеди учит людей именно этому: «Итак будьте совершенны как совершен Отец ваш Небесный» (Мф 5: 48).

По мнению Знаменского, трагические раздвоенности в личности Ницше бросают тень и на его Übermensch-a: это мечта, идея о высшем призвании и цели человека с оттенком героического пессимизма и трагического пафоса. К такому выводу приходит и Вяч. Иванов в эссе «Ницше и Дионис». Самая важная разница между ницшеанским и русскими религиозно-философскими концептами (например, у Соловьева, Иванова, Бердяева, С. Булгакова) состоит в том, что идеал Ницше и его трагический героизм не ведут к обожению «сверхчеловека», а остаются в пределах посюстороннего мира.

Übermensch Ницше и великие - с оттенками демоничости - образы Достоевского (Раскольников, Ставрогин, Иван Карамазов) не совпадают полностью, лишь соприкасаются в некоторых пунктах, но для Соловьева ницшеанский Übermensch и русские варианты одинаково оказались вдохновляющими источниками построения собственного взгляда, хотя его концепция коренится прежде всего в Евангелиях. У Ницше этот концепт появляется в мифологической оболочке, имеет языческую окраску; Übermensch-Zarathustra «по высям творения, как Бог» шагает (цитируя слова Тютчева из стихотворения «Сон на море»), и провозглашает культ сильного, прекрасного человека, представляя собой бунт против филистеров, мелких, ложных, утилитарных интересов настоящего - «христианского»! - человечества. У Достоевского же изображаются характеры с определенной психикой, в координатах земной жизни, в реальном времени и пространстве; они могут восприниматься читателем (конечно, условно) как люди - но люди необыкновенные. Одновременно под общественными определенностями скрываются и символические значения, выходящие за пределы реалистического уровня романного мира, и открывающиеся лишь при глубоком прочтении произведений. Вопрос Достоевского - в понимании Вяч. Иванова и некоторых других философов начала XX века - заключается в следующем: из потенциальных представителей «сверхчеловека» (т. е. сильных по характеру, имеющих глубокое сердце и высокий ум) кто пойдет по истинному «сверхчеловеческому пути» к обожению, а кто останется в плену «могучего, темного» царя мира, Антихриста? В великом пятикнижии Достоевского изображаются различные фазисы этого пути: желание переступить обыкновенные этические пределы человека («дрожащей твари» - по выражению Раскольникова), испытание собственной силы 
и власти (Ставрогин) и Богоборчество (Иван Карамазов). Разоблачение ложных идей и вызываемый им духовный кризис их представителей, однако, придают этим персонажам своего рода трагическую, демоническую красоту, что свидетельствует о том, что писатель понимает «титанические» стремления человека и даже в некоторых случаях сострадает пораженным через Зло героям. Положительный путь к сверхчеловеческому бытию Достоевский считает возможным - как и Вл. Соловьев - лишь на основе евангельского учения; в образах старца Зосимы и Алеши Карамазова он пытается показать перспективы духовного перерождения смертного, греховного человека.

Для литературной критики и философской эссеистики Серебряного века особенно интересными стали «демоны» (среди них Ставрогин, великий инквизитор) и герои с раздвоенной душой Достоевского (подпольный человек, Раскольников, Иван Карамазов); в интерпретациях Вяч. Иванова, В. Розанова, Д. С. Мережковского, С. Булгакова, Л. Шестова, Н. А. Бердяева и других авторов разбор этих сложных, противоречивых характеров продолжается во внероманной плоскости, в которой отражается и миросозерцание анализирующего субъекта. В анализах Розанова, С. Булгакова, Бердяева, например, «великий инквизитор» выступает почти как собеседник, с которым авторы ведут страстную полемику. На его образ тоже бросается отблеск «темной красоты», тень страдающей души, и из-за этого невозможно толковать его в упрощенном отрицательном значении - хотя интерпретаторы остро чувствуют и выявляют опасность и актуальность соблазна этого «(со)страдающего демона». Таким образом перед нами развертываются разные оттенки в понимании Зла - под влиянием декадентских веяний, революционных настроений рубежа XIX-XX вв., а также религиозного ренессанса эпохи. В оживленных философских исканиях порубежной эпохи слова «сверхчеловек», «самосовершенствование», «демон», «добро», «зло» наделяются различными, часто противоположными значениями. Из этого «общего хора» можно выделить несколько характерных мотивов, среди них, например, концепцию о двух ипостасях Зла (Люцифер и Ариман) у Вяч. Иванова, соблазн могучего и умного духа в интерпретациях «Великого инквизитора» Бердяевым и С. Булгаковым (об этом вопросе подробнее см. Дуккон 2016), или тонкие эстетические замечания о демонической красоте у Иннокентия Анненского.

Среди интерпретаций таинственной, двусмысленной природы красоты можно выделить врубелевские изображения Демона Лермонтова, но особенный интерес к Лермонтову появляется и у Соловьева, Иванова, Анненского, Блока, они тоже посвятили статьи творчеству и «демоничности» поэта. Надо заметить, что для представителей этого поколения обнаруживается глубокое родство между богоборчеством Лермонтова и Достоевского. Они осознают и их различия, как, например, свойственные Достоевскому стремления положительным образом преодолеть чувство обреченности, силу отрицания и искушение неверия. Известно, что в 1891 г. Врубель готовил серию иллюстраций к произведениям в юбилейном издании собрания сочинений поэта. Но его пленение Демоном Лермонтова началось немножко раньше, в киевский 
период жизни. Врубель воспринимает Демона в ключе символизма, придает ему прекрасный, меланхолический, страдающий облик, и в этом понимании отражается и его собственное духовное лицо, что напоминает нам миф Наркиссоса: как будто в зеркале лермонтовского демона он узнавал собственное лицо. Известно его возражение на обвинения современниками в тяготении $\kappa$ отрицательному началу:

Но, как говорил сам Врубель, Демона не понимают - путают с чертом и дьяволом, тогда как «черт» по-гречески значит просто «рогатый», дьявол - «клеветник», а «Демон» значит «душа» и олицетворяет собой вечную борьбу мятущегося человеческого духа, ищущего примирения обуревающих его страстей, познания жизни и не находящего ответа на свои сомнения ни на земле, ни на небе (http://vrubel-lermontov.ru/analyse.php).

В философии Платона (см. Апологию Сократа) $\alpha і \mu \omega v$ - это тот загадочный, божественный дух, который вступает в связь с человеком, то «нудит его и просит» (выражаясь опять словами Тютчева), то ведет его к определенному поступку. По греческо-русскому словарю А. Д. Вейсмана $\delta \alpha i ́ \mu \omega v-б о-$ жество, доброе и злое; слово может означать и судьбу (тоже добрую и злую), и может означать низшее божество, нечто среднее между $\theta \varepsilon \dot{\varsigma} \varsigma$ и ВейсмАн 1991: 282). Мы указываем на этот словарь именно по тому, что пятое издание его появилось еще в 1899 г. в Санкт-Петербурге, как раз в тот период, когда выходили на свет вышеупомянутые литературные и философские эссе. А в Новом Завете $\delta \alpha i \mu \omega v$ обозначает «злой дух», «бес». Подчеркнем, что авторы религиозно-философских толкований придерживаются новозаветного понимания демона - а Врубель - quasi-сократического.

Демон для Врубеля - не черт, не Сатана, не однозначное воплощение Зла, а олицетворение внутренней борьбы человеческой души; напомню здесь исповедь Димитрия Карамазова: «Тут дьявол с богом борется, а поле битвы сердца людей» (ДостоЕвский 1976: 100). Последнее десятилетие XIX века это начало ранней разработки наследия Достоевского, открытие значения его могучих образов. И если мы с этой стороны подходим к вопросу толкования демонических фигур Достоевского философами и литераторами Серебряного века, мы увидим, как сильно пленяли многих представителей порубежного поколения образы Раскольникова, Ивана Карамазова, великого инквизитора, Ставрогина. Они стали для них намного более значительными, чем просто художественные, «литературные» факты. Предствители порубежного поколения стремятся раскрыть онтологическое и антропологическое значение данного образа, чувствуют его вес и даже переживают всю сложность и серьезность этих литературных образов. Таким образом, как бы осуществляется цитированное выше желание С. Булгакова о раскрытии философского значения романов Достоевского.

Художественная интерпретация лермонтовского Демона Врубелем может служить аналогией тому, как относились интерпретаторы к богоборчеству героев Достоевского. Через эти фигуры открылась и возможность для 
определения собственного художественного или духовного кредо. Полемический тон статей часто приобретает страстный, вдохновенный характер, и не случайно, что в этот период русского восприятия Достоевского не найти нейтрального, «научного» толкования его героев. Именно поэтому субтекст, риторика и стилистика этих эссе могут обнаружить для исследователей новые аспекты и мысли.

И. Анненский - тонкий эстет: он подходит к темным, демоническим героям Достоевского более лирически, понимая и выявляя внутреннего человека, мечтателя из «Белых ночей», господина Прохарчина, Свидригайлова, Раскольникова - со всеми их противоречиями. В фигурах, одержимых мелкими, пошлыми или крупными грехами, Анненский узревает момент страдания. Он называет Достоевского поэтом совести, и различает в его романах два типа совести: первый тип - это совесть активная, как совесть Раскольникова, а второй - это совесть Свидригайлова, пассивная, которая «растет молча, незаметно, пухнет, как злокачественный нарост... и человек гибнет наконец от задушения в кругу, который роковым образом оцепляет его у́же и у́же» (Анненский 1988c: 638). Раскольникова Анненский считает избранником жизни, влюбленным в нее. Эта жизнь увлекает Раскольникова все дальше и дальше, как Мефистофель, «не давая ему опомниться» (Анненский 1988a: 527). По видению Анненского, и Раскольников принадлежит к «демонизированным героям» Достоевского, но именно активная совесть, после мучений, излечит раны его сердца. В начале романа находим и характерный признак этого свойства, а именно сумрачную красоту фигуры: «Кстати, он был замечательно хорош собою, с прекрасными темными глазами, темно-рус, ростом выше среднего, тонок и строен» (ДостоЕвский 1973: 6). И позже, в разговоре с Порфирием, Раскольников указывает и на другую черту, которая вызывает в памяти читателя романтических, байроновских мятежников и Übermensch Ницше: «Страдание и боль всегда обязательны для широкого сознания и глубокого сердца. Истинно великие люди, мне кажется, должны ощущать на свете великую грусть, - прибавил он, даже не в тон разговора» (Достоввский 1973: 203).

Анненский подчеркивает двойственную трактовку красоты у Достоевского: женская красота может быть силой, угрозой, в ней таятся муки и горе, но носительницы («инфернальницы») скорее есть мученицы, пленницы этой власти. Они - заключенныле ада (КАСАТкинА 2012: 90-92). А мужская красота носит всегда демонический характер: «Но красота мужчины масочна, и за нею всегда ищи или зверства, или низкой похоти, она фальшива, она не нужна, и потому она развратна» (Анненский 1988b: 535). Это суждение соприкасается и с концепцией Вяч. Иванова, который под красивыми личинами распознает демонов, в первую очередь в образе Ставрогина.

В статьях Иванова основной категорией является двойственность Зла: в ипостаси Люцифера (Денницы) дается образ соблазняющего, «прекрасного» аспекта греха: гордыня, любование собственным творчеством. «Фосфорически светящий демон» Лермонтова, «страшный, могучий и умный дух» 
великого инквизитора соблазняет человека личиной страдающего альтруиста и умом, и передает во власть другого аспекта Зла, «тлетворного и злобного» Аримана. Иванов так пишет об отношении к соблазну эстетизирования Зла некоторыми современниками:

Они явственно видят, что вся человеческая культура созидается при могущественном и всепроницающем соучастии и содействии Люцифера, что наши творческие, как и наши разрушительные энергии - в значительной части его энергии, что через него мы бываем так красивы смелостью почина, дерзостью самоутверждения, отвагою борьбы - и пусть даже несчастны, но и самим красивым страданием нашим так горделиво упоены (ИвАнов 1979: 245).

Мнение Иванова звучит однозначно: романтическая прелесть демонизма для многих современников покрывает лишь сущность проблемы: пленение человека и тоску пленника по Богу. И лечение от этой болезни эпохи он видит в христианстве:

И одно христианство учит тому, как Люцифер в человеке окончательно преодолевается Богочеловеческим Ликом, а через то побеждается и Ариман. Ибо, раз дан Богочеловеческий Лик, - дано и воскресение (ИвАнов 1979: 246).

Трагедию Ставрогина Иванов трактует тоже по концепции двух обличий Зла: ему присуща телесная красота Денницы / Люцифера (с атрибутами гордыни, вызова и духовного отъединения). Но Люцифер предает его Ариману, разлагающему духу:

Он нужен злым силам своею личиною, - нужен, как сосуд их воли и проявитель их действия; своей же воли уже вовсе не имеет. Изменник перед Христом, он неверен и Сатане. Ему должен он предоставить себя, как маску, чтобы соблазнить мир самозванством, чтобы сыграть роль лже-Царевича, - и не находит на то в себе воли. [...] Но измена Сатане не лишает его страдательной роли восприимчивого проводника и носителя сатанинской силы, которая овладевает вокруг него и через него стадом одержимых (ИвАнов 1987: 442-443).

В настоящем изложении мы постарались указать на своеобразные модификации концепта «сверхчеловек» в русской культуре второй половины XIX века. Сопоставление размышлений столь различных авторов как Вл. Соловьев, С. П. Знаменский, Вяч. Иванов и И. Анненский свидетельствует о том, как интенсивно пульсировало это понятие в русской мысли порубежной эпохи. Стоит задуматься над мнением о том, что феномен «сверхчеловек» появился в русской литературе далеко не под влиянием Ницше; по следам Пушкина, Лермонтова, Тургенева, Достоевского и русского гамлетизма уже постепенно выкристаллизовались те общественные, моральные, теологические и экзистенциальные проблемы, которые нашли художественное выражение в таких образах как «лишний человек», «подпольный человек», «смешной человек». В этой цепи «сверхчеловек» имеет наиболее глубокие философские значения, которые остались актуальными и до наших дней. 


\section{Литература}

Анненский 1988a = Анненский И. Мечтатели и избранник. В кн.: АннЕнский И. Книги отражений. Ленинград, 1988. 523-528.

Анненский $1988 \mathrm{~b}=$ Анненский И. Символы красоты у русских писателей. В кн.: Анненский И. Книги отражений. Ленинград, 1988. 528-536.

АнненскИй 1988c = Анненский И. Достоевский. В кн.: Анненский И. Книги отражений. Ленинград, 1988. 634-641.

БОГДАНОВА 2008 = БОГДАНОВА О. А. Под созвездием Достоевского. Художественная проза рубежа XIX-XX веков в аспекте жанровой поэтики русской классической литературы. Москва, 2008.

БулгАКОВ 1991 = БулГАКОВ С. Н. Иван Карамазов в романе Достоевского «Братья Карамазовы» как философской тип. В кн.: СЕливеРстов Ю. И. (ред.) О великом инквизиторе. Достоевский и последующие. Москва, 1991. 193-217.

ВЕЙСМАН 1991 = ВЕЙСМАН А. Д. Греческо-русский словарь. Москва, 1991.

ДостоЕВСКИй 1973 = ДостоЕВСКИй Ф. М. Полное собрание сочинений в 30 томах. Т. 6. Преступление и наказание. Ленинград, 1973.

ДостоЕВСКий 1976 = ДостоЕВский Ф. М. Полное собрание сочинений в 30 томах. Т. 14. Братья Карамазовы. Ленинград, 1976.

Дуккон 2014 = Дуккон А. «Образы» Лермонтова в статьях В. Г. Белинского и Вл. Соловьева. In: Lermontov in 21st-century Literary Criticism / Лермонтов в литературной критике XXI века. Budapest, 2014. 42-49.

Дуккон $2016=$ Дуккон А. Эсхатологичность Ф. М. Достоевского в интерпретации Н. А. Бердяева и С. Н. Булгакова. В кн.: Утопия и эсхатология в культуре русского модернизма. Москва, 2016. 390-407.

ЗНАМЕНСКИй 2001 = ЗНАмЕНСКИй С. П. «Сверхчеловек» Ницше. В кн.: Нuџщее: Pro et contra. Санкт-Петербург, 2001. 924-965.

Иванов 1971 = Иванов В. И. Ницше и Дионис. В кн.: ИвАНов В. И. Собрание сочинений в 4 томах. Т. 1. Брюссель, 1971. 715-726.

ИвАНОВ $1979=$ ИвАНОВ В. И. Пролегомены о демонах. В кн.: ИвАНОВ В. И. Собрание сочинений в 4 томах. Т. 3. Брюссель, 1979. 243-252.

ИвАНОВ 1987 = ИванОВ В. И. Основной миф в романе «Бесы». В кн.: ИвАнОВ В. И. Собрание сочинений в 4 томах. Т. 4. Брюссель, 1987. 437-444.

КАСАТКИНА $2007=$ КАСАТКИНА Т. А. (ред.) Достоевский и ХХ век. Т. 1-2. Москва, 2007.

КАСАТКИНА 2012 = КАСАТКИНА Т. А. О философском язЫКе Ф. М. ДостоевскоГО. В кН.: Ф. М. Достоевский. Писатель, мыслитель, провидец. Москва, 2012. 90-97.

КЕлдыш 1992 = КЕлдыш В. А. Наследие Достоевского и русская мысль порубежной эпохи. В кн.: Связь времен. Проблемы преемственности в русской литературе конца ХІХ-начала ХХ в. Москва, 1992. 76-115.

СоЛовьев $1990 \mathrm{a}=$ Соловьев В. С. Лермонтов. В кн.: СоЛовьЕВ В. С. Литературная критика. Москва, 1990. 274-291.

Соловьев $1990 \mathrm{~b}=$ Соловьев В. С. Идея сверхчеловека. В кн.: СоЛовьЕВ В. С. Сочинения в 2 томах. Т. 2. Москва, 1990. 626-634.

Goethe 1972 = Goethe J. W. Faust. Gesamtausgabe. Leipzig, 1972.

JACKSON 1993 = JACKSON R. L. Dialogues with Dostoevsky. The Overwhelming Questions.

Stanford, 1993. 